\title{
Differential Requirement of the Ribosomal Protein S6 and Ribosomal Protein S6 Kinase for Plant-Virus Accumulation and Interaction of S6 Kinase with Potyviral VPg
}

\author{
Minna-Liisa Rajamäki, ${ }^{1}$ Dehui Xi, ${ }^{2}$ Sidona Sikorskaite-Gudziuniene, ${ }^{1}$ Jari P. T. Valkonen, ${ }^{1}$ and \\ Steven A. Whitham ${ }^{3}$ \\ ${ }^{1}$ Department of Agricultural Sciences, P.O. Box 27, FI-00014 University of Helsinki, Helsinki, Finland; ${ }^{2}$ College of Life Science, \\ Sichuan University, Chengdu, 610064, China; and ${ }^{3}$ Department of Plant Pathology and Microbiology, lowa State University, \\ Ames 50011, U.S.A.
}

Accepted 2 March 2017.

\begin{abstract}
Ribosomal protein S6 (RPS6) is an indispensable plant protein regulated, in part, by ribosomal protein $\mathrm{S6}$ kinase (S6K) which, in turn, is a key regulator of plant responses to stresses and developmental cues. Increased expression of RPS6 was detected in Nicotiana benthamiana during infection by diverse plant viruses. Silencing of the RPS6 and S6K genes in N. benthamiana affected accumulation of Cucumber mosaic virus, Turnip mosaic virus (TuMV), and Potato virus A (PVA) in contrast to Turnip crinkle virus and Tobacco mosaic virus. In addition, the viral genome-linked protein (VPg) of TuMV and PVA interacted with S6K in plant cells, as detected by bimolecular fluorescence complementation assay. The VPg-S6K interaction was detected in cytoplasm, nucleus, and nucleolus, whereas the green fluorescent protein-tagged S6K alone showed cytoplasmic localization only. These results demonstrate that the requirement for RPS6 and S6K differs for diverse plant viruses with different translation initiation strategies and suggest that potyviral $\mathrm{VPg}-\mathrm{S6K}$ interaction may affect S6K functions in both the cytoplasm and the nucleus.
\end{abstract}

The ribosome catalyzes protein translation in all organisms. It is a ribonucleoprotein particle of 70 Svedberg units (70S) in prokaryotes and $80 \mathrm{~S}$ in eukaryotes, composed of two subunits (30S and 50S in prokaryotes and $40 \mathrm{~S}$ and $60 \mathrm{~S}$ in eukaryotes). In eukaryotes, the large subunit is composed of 25 to $28 \mathrm{~S}, 5.8 \mathrm{~S}$, and 5S ribosomal RNA (rRNA) together with approximately 47 ribosomal proteins ( $\mathrm{r}$-proteins), whereas the small subunit is composed of 18S rRNA and approximately 33 r-proteins (Byrne 2009). The rRNA provides the catalytic activity for decoding

\section{M.-L. Rajamäki and D. Xi contributed equally to the study.}

Nucleotide sequence data is available in the GenBank/EMBL databases under accession numbers LT724245 (StRPS6a), LT724246 (StRPS6b), LT724247 (StS6Ka), and LT724248 (StS6Kb).

Current address of S. Sikorskaite: Institute of Horticulture, Lithuanian Research Centre for Agriculture and Forestry, Kaunas, Lithuania.

Corresponding author: M.-L. Rajamäki; E-mail: minna.rajamaki@ helsinki.fi

*The $\boldsymbol{e}$-Xtra logo stands for "electronic extra" and indicates that one supplementary table and six supplementary figures are published online.

(c) 2017 The American Phytopathological Society messenger RNA (mRNA) into peptides and to interact with the transfer RNA (tRNA) during translation by providing peptidyl transferase activity. Many r-proteins have RNA chaperone activity thought to assist in proper folding of specific domains of the rRNA subunits to assemble and maintain the structure of mature ribosomes (Semrad et al. 2004). In addition to their importance in translation, some r-proteins appear to possess regulatory functions in fundamental processes related to the cell cycle, apoptosis, development, oncogenesis, and control of rDNA transcription (Chen and Ioannou 1999; Jeon et al. 2008; Kim et al. 2014; Lindström 2009; Panić et al. 2007).

Viruses are obligate intracellular pathogens that must parasitize their host's ribosomes to produce structural and nonstructural proteins from their genomic RNA or mRNA. It is generally accepted that viral RNA are efficiently recruited to ribosomes to accomplish their translation. Most of what is known about enhanced translation involves viral-encoded cis- and transacting factors that interact with host initiation factor complexes and other factors such as poly(A) binding protein to efficiently recruit viral RNA to ribosomes (Newburn and White 2015; Nicholson and White 2011; Robaglia and Caranta 2006; Sharma et al. 2015). Unlike r-proteins, these host proteins are not primary components of the ribosome.

Relatively little is known about the roles of r-proteins in viral RNA translation in plants and other organisms. There is some evidence that potyviruses and other plant viruses can induce expression of large sets of r-proteins. Plum pox virus (PPV; genus Potyvirus) induced mRNA expression of 72 r-proteins of cytosolic ribosomes in Nicotiana benthamiana (Dardick 2007), and Turnip mosaic virus (TuMV; genus Potyvirus) induced mRNA expression of 69 r-proteins in Arabidopsis thaliana (Yang et al. 2007). Studies investigating interactions between plant and viral proteins have also implicated r-proteins as important components of host-virus interactions. The P6 protein of the plant DNA virus Cauliflower mosaic virus (genus Caulimovirus) was found in a complex with r-proteins, including RPL18, RPL24, and RPL13, as well as the translation initiation factor eIF3 (Bureau et al. 2004). The P1 protein of Tobacco etch virus (TEV; genus Potyvirus) specifically associates with 15 r-proteins of the $60 \mathrm{~S}$ ribosomal subunits and 2 r-proteins of the $40 \mathrm{~S}$ subunit (RSP6 and RPS23) at the early stages of virus infection (Martínez and Daròs 2014). The helper component proteinase (HCpro), cylindrical inclusion protein, and, putatively, also the viral genome-linked protein (VPg) of Potato virus A (PVA; genus Potyvirus) are ribosome-associated in virus-infected cells 
(Ivanov et al. 2016). In addition, the ribosomal stalk protein P0 promotes PVA translation together with VPg and host eIF4E/eIF(iso)4E (Hafrén et al. 2013). In the case of geminiviruses, RPL10 and RPL18 were found to interact with nuclear shuttle protein interacting kinase (NIK) and, subsequently, RPL10 was shown to be phosphorylated by NIK, which is a virulence target of the begomovirus nuclear shuttle protein (Rocha et al. 2008). A genome-wide screen of Drosophila melanogaster genes demonstrated the critical role of 66 r-proteins that were required for efficient replication of Drosophila C virus (Cherry et al. 2005).

Of all r-proteins, RPS6 has attracted perhaps the most attention. Until recently, it was the only r-protein known to be phosphorylated in response to changes in physiological, pathological, and pharmacological stimuli (Mazumder et al. 2003; Rocha et al. 2008). RPS6 is an indispensable r-protein that undergoes phosphorylation in response to a wide variety of stimuli, and this modification plays a critical regulatory role in multiple cellular and organismal processes (Chang et al. 2005; Meyuhas 2008). RPS6 is mainly phosphorylated by r-protein S6 kinases (S6K) (Moore et al. 2009). S6K are serine/threonine kinases and downstream components of the target of rapamycin (TOR) signaling pathway (Mahfouz et al. 2006; Xiong and Sheen 2014). Several reports have demonstrated that RPS6 is subject to phosphorylation in response to human or animal viral infection. In most of those cases, the phosphorylation of RPS6 is downregulated. For example, RPS6 phosphorylation is dramatically diminished within hours after infection with alphaviruses, which is thought to contribute to differential translation of host and viral mRNA (Montgomery et al. 2006).

We previously showed that RPS6 is required for accumulation of two viruses that use cap-independent translation strategies: TuMV (genus Potyvirus; family Potyviridae) and Tomato bushy stunt virus (TBSV; genus Tombusvirus; family Tombusviridae) (Yang et al. 2009). In contrast, accumulation of Tobacco mosaic virus (TMV; genus Tobamovirus; family Virgaviridae), a virus with capped genomic RNA and mRNA, was not dependent on RPS6 (Yang et al. 2009). This differential requirement for RPS6 was not a general property, because four other r-proteins that were silenced were all required for accumulation of TuMV, TBSV, and TMV. Here, we further investigated the relationships between viral translation strategies and a requirement for RPS6 by testing three additional viruses: Cucumber mosaic virus (CMV; genus Cucumovirus; family Bromoviridae) that has a capped RNA, and Turnip crinkle virus (TCV; genus Carmovirus; family Tombusviridae) and Potato virus A (PVA; genus Potyvirus; family Potyviridae) that have uncapped RNA. PVA was included in some of the experiments in addition to TuMV to generalize the results in potyviruses. Moreover, PVA proteins have been previously shown to associate with ribosomes and PVA translation is promoted by the ribosomal stalk protein P0 (Hafrén et al. 2013; Ivanov et al. 2016). In addition, the requirement of $\mathrm{S} 6 \mathrm{~K}$ for viral accumulation in $N$. benthamiana was investigated using multiple viruses. Furthermore, the aim was to test whether the VPg of the studied potyviruses (TuMV and PVA) interacts with RPS6 or S6K.

\section{RESULTS}

\section{Diverse plant viruses induce the expression of RPS6 protein in $N$. benthamiana.}

Our previous work demonstrated that the mRNA transcripts of large groups of r-protein genes were upregulated in response to TuMV in Arabidopsis (Yang et al. 2007). Furthermore, we showed that TuMV and TEV as well as TMV could induce mRNA expression of RPS6 and other r-protein genes (Yang et al. 2009). However, the question remains as to whether increased levels of RPS6 protein also occur. To investigate the effects of diverse viruses on the accumulation of NbRPS6 protein, $N$. benthamiana plants were rub inoculated with TuMV, CMV, TCV, and TMV. Systemically infected leaf tissues were harvested at 8 days postinoculation (dpi), and RPS6 was detected by Western blot using a maize RPS6 antiserum (Williams et al. 2003). The increased intensity of the RPS6 band in the virusinfected samples relative to the mock-inoculated control showed that the four viruses can induce the expression of RPS6 in $N$. benthamiana at the protein level (Fig. 1; Supplementary Fig. S1). These results demonstrate not only that can the viruses induce expression of RPS6 mRNA but also that there is a concomitant increase in the levels of the encoded protein.

\section{S6K- and RPS6-silenced $N$. benthamiana plants show similar phenotypes.}

To test whether RPS6 phosphorylation was required for CMV, TCV, TMV, and TuMV infection, a 515-bp fragment of the $S 6 K$ gene was amplified and cloned into a Tobacco rattle virus (TRV) vector and used to silence $S 6 K$ in $N$. benthamiana (Dinesh-Kumar et al. 2003; Liu et al. 2002). The N. benthamiana plants in which $S 6 K$ was silenced by virus-induced gene silencing (VIGS) were characterized by chlorotic leaves and some degree of arrested growth, with sporadic necrosis on the oldest leaves (Fig. 2A). This phenotype resembles somewhat the RPS6silenced plants (TRV::RPS6) (Fig. 2A) (Yang et al. 2009). To confirm that the VIGS constructs effectively silenced the $S 6 K$ gene, reverse-transcription polymerase chain reaction (RT-PCR) was performed on total RNA extracted from systemic leaves sampled at 10 days postsilencing agroinfiltration with TRV constructs. The mRNA transcripts of $S 6 K$ were reduced in the VIGS plants when compared with the nontreated or TRV emptyvector (TRV::00) plants (Fig. 2B).

\section{Effects of S6K silencing on CMV, TCV, TMV, TuMV, and PVA infection in $N$. benthamiana.}

To determine the effect of S6K depletion on virus accumulation, silenced $N$. benthamiana plants as well as TRV:: 00, TRV::RPS6, and mock-inoculated control plants were infected with CMV, TCV, TMV, and TuMV. Inoculated leaves were collected at $6 \mathrm{dpi}$ and Northern blot was performed to detect the accumulation of virus genomic (+)RNA. Northern blot analysis showed that the mRNA transcripts of TuMV and CMV were reduced in $S 6 K$-silenced plants and almost could not be detected in RPS6-silenced plants compared with nontreated or TRV::00 plants (Fig. 3A and D). In contrast, the levels of mRNA transcripts of TMV were similar in $S 6 K$-silenced, RPS6-silenced, and TRV::00 plants (Fig. 3C). The mRNA transcripts of TCV were reduced in RPS6-silenced plants and less reduced in $S 6 K$-silenced plants (Fig. 3B). These data demonstrate that RPS6 and S6K are necessary for TuMV and CMV accumulation, TCV has

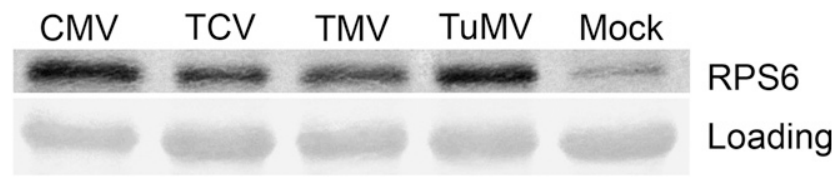

Fig. 1. Accumulation of RPS6 protein at 8 days postinoculation in systemic leaves of Nicotiana benthamiana plants infected with Cucumber mosaic virus (CMV), Turnip crinkle virus (TCV), Tobacco mosaic virus (TMV), and Turnip mosaic virus (TuMV). Mock indicates plants that were rub inoculated with leaf sap of an uninfected plant ground in phosphate buffer. In each lane, $30 \mu \mathrm{g}$ of total protein was loaded and separated by sodium dodecyl sulfate polyacrylamide gel electrophoresis, and RPS6 protein was detected by immunoblot assay using an RPS6 protein antiserum (Williams et al. 2003). Equal loading was controlled by staining the membranes with Ponceau $\mathrm{S}$ solution. The experiment was repeated two times with similar results. 
some degree of requirement for its accumulation, but TMV accumulation is independent from RPS6 and S6K.

Infectious viral RNA was used as an inoculum source to exclude some potential complications such as the cotranslational disassembly of virions and to visualize possible changes of virus accumulation in plants after $S 6 K$ had been silenced. The first true leaves of $N$. benthamiana plants were inoculated with TRV::00, TRV::S6K, and TRV::RPS6 and, 10 days later, the upper leaves were inoculated with TuMV-green fluorescent protein (GFP) and TMV-GFP by Agrobacterium infiltration. In agreement with the sap inoculation experiments, TMV-GFP fluorescence in $S 6 K$ - and RPS6-silenced leaves developed similarly to that in nonsilenced control plants at 5 dpi (Fig. 4A). Only weak to no GFP fluorescence was detected following agroinfiltration of TuMV-GFP in the $S 6 K$ - and RPS6-silenced plants (Fig. 4B). As with TMV-GFP, the TuMV-GFP results mirrored those from the sap inoculation experiments.

To extend these findings to potyviruses more generally, we tested whether silencing RPS6 and S6K affected accumulation and movement of PVA. Results similar to those for TuMV were obtained when PVA-GFP was inoculated to the upper leaves of $S 6 K$ - and RPS6-silenced $N$. benthamiana plants by agroinfiltration. No or very weak fluorescence was detected in plants silenced for RPS6 (Supplementary Fig. S2). In $S 6 K$-silenced plants, the GFP fluorescence was reduced as compared with nonsilenced control plants but less than in RPS6-silenced plants (Supplementary Fig. S3).

\section{Subcellular localization of RPS6 and S6K.}

To better understand the roles of RPS6 and S6K in potyvirus infection, the subcellular localization of proteins was studied in

A
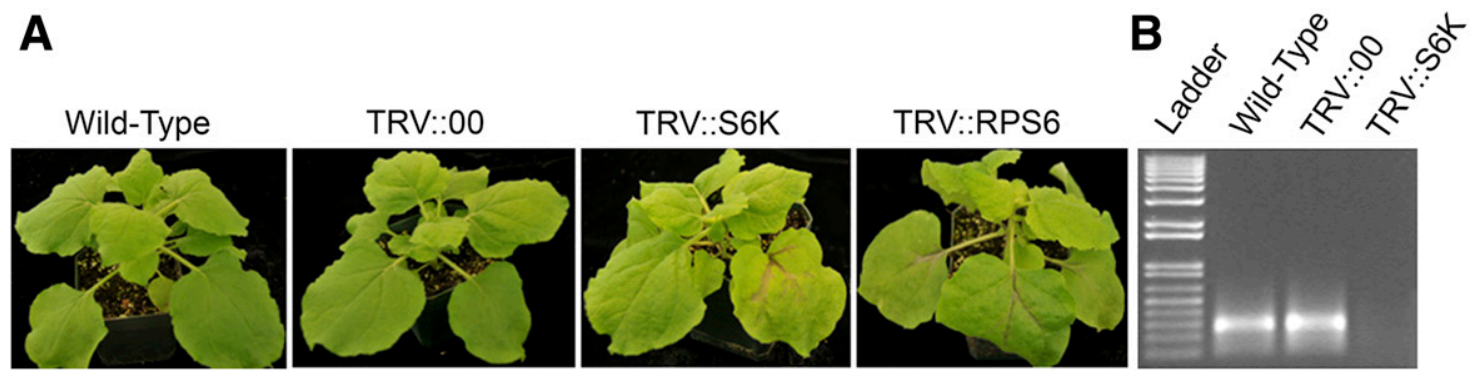

Fig. 2. Virus-induced gene silencing of S6K and RPS6 in Nicotiana benthamiana. A, Phenotype of wild-type plants, Tobacco rattle virus (TRV)::00 control plants, and TRV::S6K- or TRV::RPS6-silenced plants at 10 days postagroinfiltration. B, Reverse-transcription polymerase chain reaction analysis of $S 6 K$ mRNA levels in wild-type plants, TRV::00 control plants, and TRV::S6K-silenced plants at 10 days postagroinfiltration. Ladder indicates 1-kb plus DNA ladder (Invitrogen).
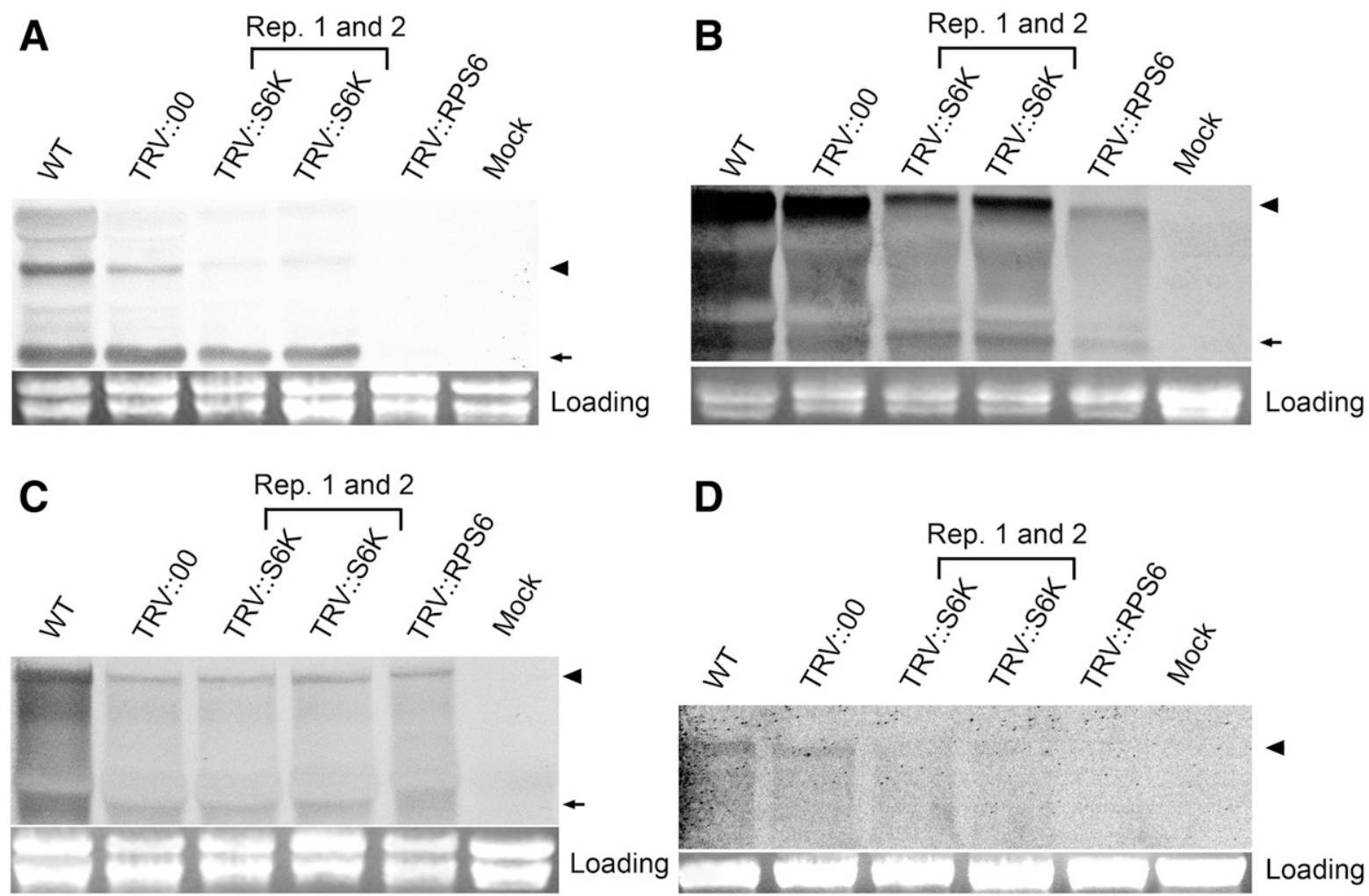

Loading

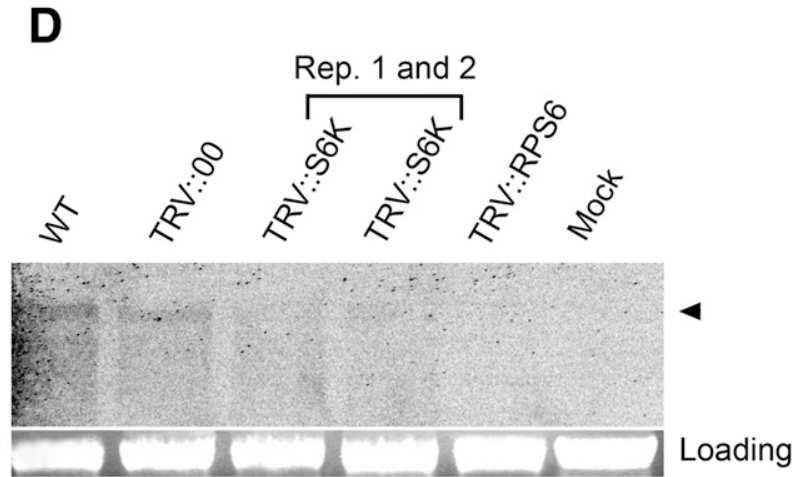

Fig. 3. Northern blot analysis of the accumulation of A, Cucumber mosaic virus (CMV); B, Turnip crinkle virus (TCV); C, Tobacco mosaic virus (TMV); and D, Turnip mosaic virus (TuMV) in wild-type (WT) plants, Tobacco rattle virus (TRV)::00 control plants, and TRV::S6K- or TRV::RPS6-silenced plants at 6 days postinoculation. Data for the two independent replicates for TRV::S6K-silenced plants are shown. WT Nicotiana benthamiana plants received no pretreatment prior to inoculation with the respective plant viruses. TRV::00 indicates $N$. benthamiana plants that were infected with the empty TRV vector Plants were inoculated with the secondary virus (CMV, TCV, TMV, or TuMV) 10 days after TRV inoculation to leaves at positions $+3,+4$, or +5 above the TRVagroinfiltrated leaf. Arrowheads indicate the positions of viral genomic RNA and arrows indicate positions of subgenomic RNA. 
plant cells. The fluorescence from RPS6-GFP (and GFP-RPS6) was detected almost exclusively in the nucleus, where the protein was concentrated in the nucleolus and the inner border regions of the nucleolus (Fig. 5A). In addition, the protein was found in numerous small subnuclear bodies. The localization of RPS6 remained similar in potyvirus (PVA-GFP)-infected cells. Coexpression of PVA VPg-monomeric red fluorescent protein (mRFP), which shows strong nuclear and nucleolar localization (Rajamäki and Valkonen 2009), and RPS6-GFP indicated colocalization of the proteins in the nucleus and nucleolus (Fig. 5C).

In contrast to RPS6, GFP-S6K localized to cytoplasm and was perinuclear. No or very little visible fluorescence was observed in the nucleus (Fig. 5B). The localization pattern of S6K-GFP was similar to GFP-S6K but weaker fluorescence was observed. Therefore, GFP-S6K was used in all further experiments. As with RPS6, the localization of GFP-S6K did not change during potyvirus infection or coexpression of GFPS6K and PVA VPg-mRFP (Fig. 5D). Therefore, although RPS6 is regulated by $\mathrm{S} 6 \mathrm{~K}$, their predominant observed localization patterns in plant cells were different under these sets of conditions.

\section{PVA-VPg interacts with S6K.}

The essential roles of RPS6 and S6K in potyvirus infection prompted us to examine whether one or both of the proteins could directly interact with potyviral proteins. The sequences encoding RPS6 and S6K of Arabidopsis and potato (Solanum tuberosum) were amplified from the corresponding cDNA and cloned into yeast two-hybrid system (YTHS) vectors. Arabidopsis has two functionally equivalent RPS6 variants (AtRPS6a and AtRPS6b) that differ at 14 amino acid residues (Creff et al. 2010). The Arabidopsis genes of RPS6a, S6K1, and S6K2 cloned in this study were identical to The Arabidopsis Information Resource sequences AT4g31700.1, AT3g08730.1, and AT3g08720.1, respectively. From potato, two variants of both RPS6 (StRPS6a and StRPS6b) and S6K (StS6Ka and $S t S 6 K b)$ were cloned. The deduced amino acid sequence of StRPS6a and StRPS6b was 249 residues and they differed at 8 amino acid positions (28Y/F, 150G/S, 152D/E, 165T/N, $168 \mathrm{~N} / \mathrm{T}, 170 \mathrm{~K} / \mathrm{T}, 173 \mathrm{E} / \mathrm{N}$, and $174 \mathrm{~V} / \mathrm{A})(88.2 \%$ nucleotide identity) (Supplementary Fig. S4). As compared with AtRPS6, StRPS6 proteins were one amino acid shorter. In addition,

A

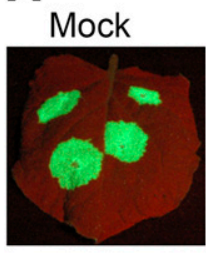
TRV::00
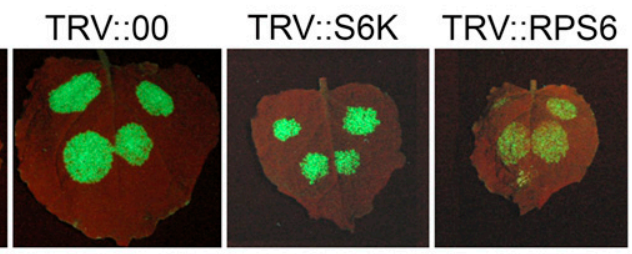

B
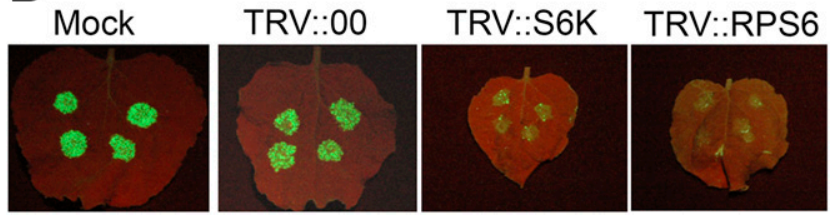

Fig. 4. Effects of silencing S6K and RPS6 genes on Turnip mosaic virus (TuMV) and Tobacco mosaic virus (TMV) accumulation in agroinoculated leaves. A, TMV-green fluorescent protein (GFP) infection in $S 6 K$ - and RPS6-silenced and control plants at 5 days after agroinoculation. B, TuMVGFP infection in $S 6 K$ - and RPS6-silenced and control plants at 5 days after agroinoculation. This time point corresponds to 15 days after Tobacco rattle virus (TRV) agroinoculation. This experiment was repeated at least three times with similar results. The RPS6 mRNA transcript levels were also analyzed in a previous study (Yang et al. 2009).
StRPS6a and StRPS6b differed by 15 and 19 amino acid residues, respectively, from AtRPS6a. The two StS6K proteins were 475 residues long and differed at only one amino acid position (E136A), and they shared 64.5 to $66.3 \%$ amino acid identity to AtS6K1 and AtS6K2 (Supplementary Fig. S5).

VPg shows strong nuclear and nucleolar localization, similar to RPS6. No interaction was detected between PVA-VPg and the AtRPS6a, StRPS6a, and StRPS6b proteins or between TuMV-VPg and AtRPS6a or AtS6K2 proteins using GAL4based YTHS. However, a strong interaction was identified between PVA-VPg and AtS6K2, and between PVA-VPg and StS6Ka and StS6Kb, as determined based on fast growth of yeast on stringent selection media (Table 1; Fig. 6). The interaction was detected when VPg was expressed fused to the activation domain (AD) and AtS6K2, StS6Ka, and StS6Kb fused to the DNA binding domain (BD) in YTHS. Moreover, PVA-nuclear inclusion protein a (NIa) interacted with AtS6K2, StS6Ka, and StS6Kb. AtS6K1 fused to the BD autoactivated reporter gene expression and could not be tested for the interaction in this orientation. Western analysis showed that all proteins were expressed, although in different amounts (Fig. 6B).

\section{Interaction of VPg with S6K localizes}

to the nucleus and nucleolus.

Bimolecular fluorescence complementation (BiFC) was used to test VPg-S6K interactions in plant cells. Both PVA-VPg and
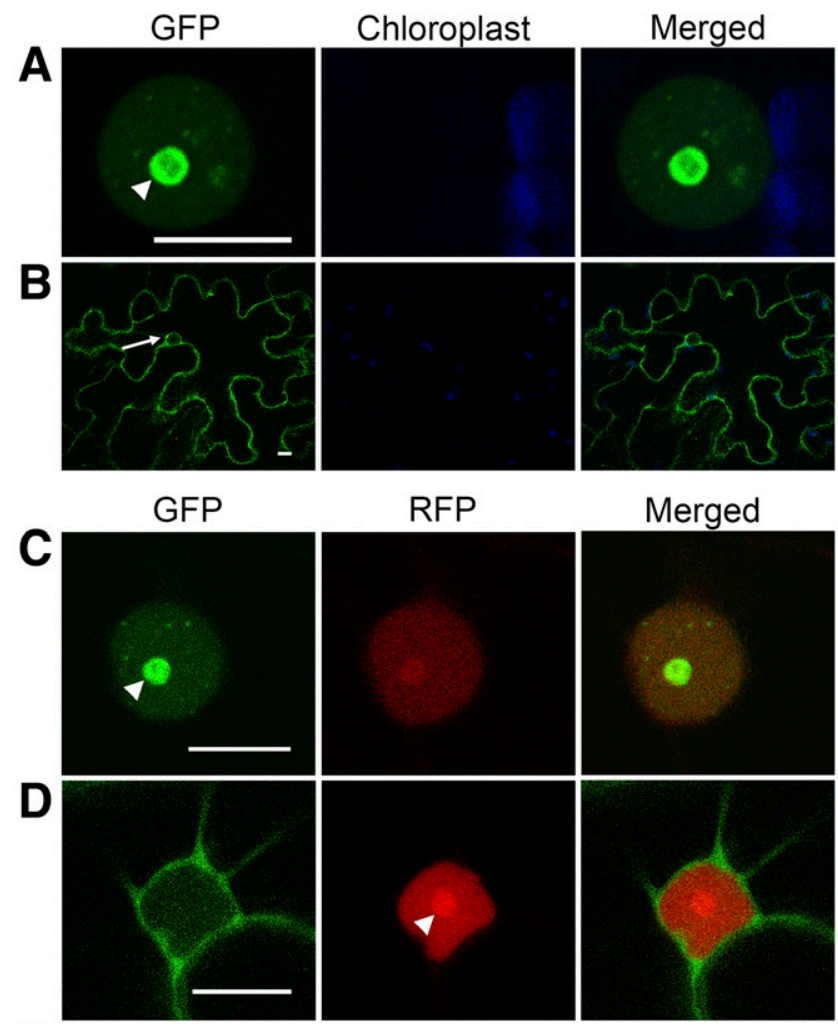

Merged

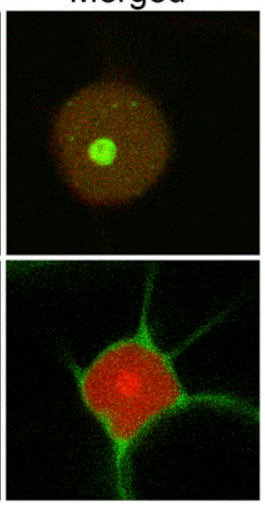

Fig. 5. Subcellular localization of green fluorescent protein (GFP)-StS6K and GFP-StRPS6 fusion proteins in leaves of Nicotiana benthamiana as detected by confocal microscopy $\mathbf{A}$ and $\mathbf{B}, 2$ and $\mathbf{C}$ and $\mathbf{D}, 3$ days after agroinfiltration. A, GFP-StRPS6a localizes to the nucleus, nucleolus, and multiple small subnuclear bodies when expressed alone. B, GFP-StS6Ka localizes mainly in cytoplasm and is absent from the nucleus when expressed alone. A close-up of the nucleus was similar to that shown in D. C, GFP-StRPS6a coexpressed with viral genome-linked protein (VPg)monomeric red fluorescent protein (mRFP); and D, GFP-StS6Ka coexpressed with VPg-mRFP. Arrow in B indicates the position of the nucleus and arrowheads in $\mathrm{A}, \mathrm{C}$, and $\mathrm{D}$ the position of the nucleolus. Scale bars $=$ $10 \mu \mathrm{m}$. 
TuMV-VPg interacted with AtS6K2 (Fig. 7). The strongest fluorescence was observed in leaf epidermal cells of $N$. benthamiana when VPg was fused to the $\mathrm{N}$ terminus of the C-terminal half of yellow fluorescent protein (YFP) (VPg-YC) and AtS6K2 to the $\mathrm{N}$ terminus of the N-terminal half of YFP (AtS6K2-YN) as examined under epifluoresence microscope 2 to 3 days postinfiltration. The fluorescence was observed in cytoplasm and in the nucleus and nucleolus (Figs. 7 and 8A and B), and also in some subnuclear bodies as analyzed by confocal microscope (Fig. 8A and B). No fluorescence was detected when AtS6K2-YN was expressed with YC-HIP1 (HCpro interacting protein 1) used as a negative control. Localization of the VPg-AtS6K2 interaction was similar in potyvirus-infected cells, as examined by coexpression of the BiFC constructs and PVA expressing mRFP-tagged 6K2 (Fig. 8C and D). Cytoplasmic localization of $\mathrm{VPg}-\mathrm{AtS6K} 2$ interaction differed from the fluorescence of 6K2-mRFP vesicles, which are the sites of viral replication (Cotton et al. 2009; Wei et al. 2010). In conclusion, the data indicated that VPg interacts with AtS6K2 in the cytoplasm, nucleus, and nucleolus.

\section{Phosphorylation of RPS6 in N. benthamiana or $S 6 K$-silenced $N$. benthamiana in response to different plant viruses.}

To investigate phosphorylation of RPS6 in response to infection by different plant viruses, r-proteins were extracted from virusinfected leaves, separated by sodium dodecyl sulfate polyacrylamide gel electrophoresis (SDS-PAGE), and stained with Pro-Q Diamond to detect phosphorylated proteins or SYPRORuby to detect total proteins. The Pro-Q Diamond stain identified a band of a similar size expected for RPS6 protein $(28.6 \mathrm{kDa})$ (Supplementary Fig. S6A and E). The intensity of the band was consistent among samples infected with TuMV, CMV, TCV, TMV, or PVA. These data suggested that there were no obvious changes in the phosphorylation level of RPS6 in response to these viruses. To directly test whether the VPg of TuMV or PVA could affect RPS6 phosphorylation, TuMV-VPg and PVA-VPg were transiently expressed in $N$. benthamiana leaves. RPS6 phosphorylation was also not obviously affected by transient expression of TuMV or PVA VPg. To confirm that silencing of $S 6 K$ with TRV::S6K could affect the phosphorylation level of RPS6, r-proteins were extracted from TRV::00, TRV::S6K, and mock-treated plants, then separated by SDS-PAGE. Staining with Pro-Q Diamond showed that the phosphorylation of RPS6 was reduced in TRV::S6K plants when compared with mock-treated and TRV::00 plants.

\section{DISCUSSION}

We have shown that plant viruses differ in their requirements for the r-protein RPS6 and the major kinase S6K that mediates its phosphorylation. The accumulation of TuMV and PVA (Potyvirus) and CMV (Cucumovirus) was dependent on RPS6 and S6K, whereas accumulation of TCV (Carmovirus) and TMV (Tobamovirus) was not. However, all of the viruses were able to induce the accumulation of RPS6 protein, suggesting that this may be a common response to (+)-stranded RNA viruses. Our data also indicated that the VPg of the potyviruses TuMV and PVA can interact with S6K. The VPg-S6K interactions were observed in the cytoplasm, nucleus, and nucleolus, suggesting that the interactions have the potential to interfere with S6K functions. These results led us to hypothesize that RPS6 phosphorylation might be altered during potyvirus infections, possibly through the VPg. In our assays, the phosphorylation of RPS6 was not obviously affected by the viruses or VPg tested.

Previous studies focused on mRNA transcript profiling of plant responses to viral infection have shown that potyviruses, in particular, are potent inducers of the transcription of genes encoding a majority of plant r-proteins (Dardick 2007; Yang
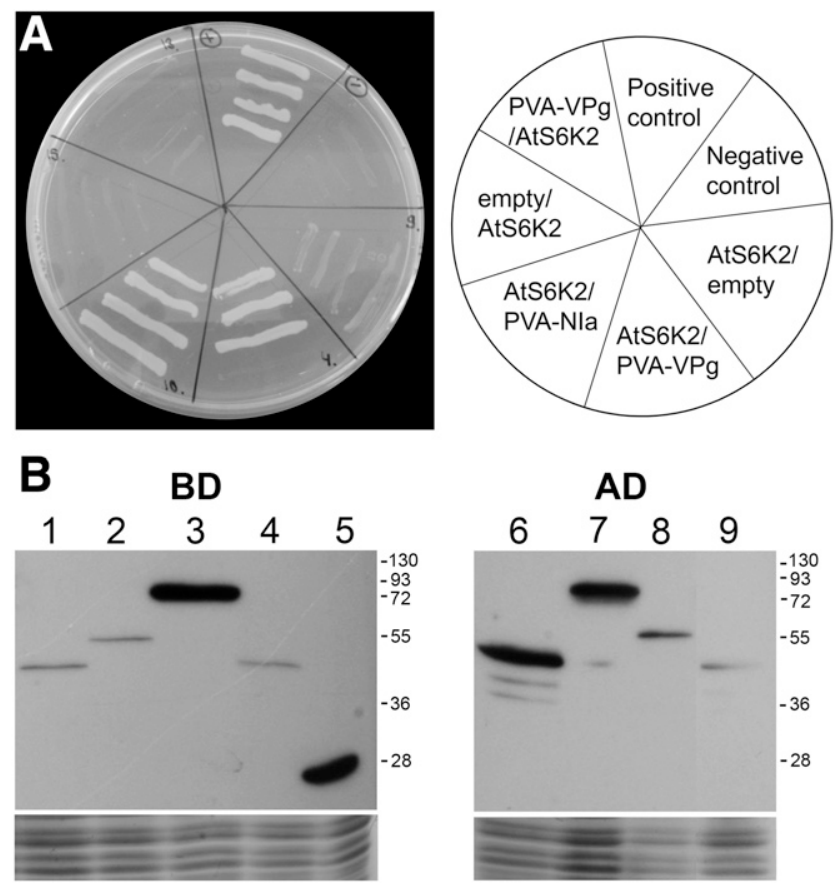

Fig. 6. Interactions between Potato virus A (PVA) viral genome-linked protein (VPg) and Arabidopsis thaliana S6 kinase (AtS6K2) using the GAL4 yeast two-hybrid system, and expression of fusion proteins in yeast. $\mathrm{A}$, Interactions of VPg and nuclear inclusion protein a (NIa) as detected based on yeast growth on stringent selection media (SD-WHAL) 3 days after plating. Proteins tested in pairs for interaction were fused to the DNA binding domain $(\mathrm{BD})$ or the activation domain $(\mathrm{AD})$, respectively (see the schematic presentation to the right; the first mentioned protein was tagged with $\mathrm{BD}$ and the latter with $\mathrm{AD}$ ). The interaction was detected only when $\mathrm{VPg}$ and NIa were expressed fused to AD and AtS6K2 fused to BD. B, Western blot analysis of the expressed fusion proteins in yeast using antibodies specific to the $\mathrm{AD}$ (lanes 1 to 5 ) or the BD (lanes 6 to 9). Lane 1, PVA-VPg; 2, AtRPS6; 3, AtS6K2; 4, Turnip mosaic virus (TuMV)-VPg; 5 , empty AD; 6, TuMV-VPg; 7, AtS6K2; 8, AtRPS6; and 9, PVA-VPg. Sizes of molecular mass markers (kDa) are shown to the left. Coomassie-bluestained sodium dodecyl sulfate polyacrylamide gel electrophoresis gel served as a protein loading control.

Table 1. Interactions between potyviral viral genome-linked protein (VPg) and ribosomal protein S6 (RPS6) and S6 kinase (S6K) from Arabidopsis and potato using yeast two-hybrid system ${ }^{\mathrm{a}}$

\begin{tabular}{|c|c|c|c|c|c|c|c|}
\hline Protein $^{b}$ & AtRPS6a & StRPS6a & StRPS6b & AtS6K2 & StS6Ka & StS6Kb & Empty \\
\hline PVA-VPg & - & - & - & $++^{\mathrm{c}}$ & $++^{\mathrm{c}}$ & $++^{\mathrm{c}}$ & - \\
\hline TuMV-VPg & - & - & - & - & - & - & - \\
\hline PVA-NIa & - & nt & nt & $++^{c}$ & $++^{c}$ & $++^{\mathrm{c}}$ & - \\
\hline Empty & - & - & - & - & - & - & - \\
\hline
\end{tabular}

\footnotetext{
${ }^{a}$ Symbols: ++ indicates strong yeast growth in 2 days on stringent selection media, - indicates no growth, and nt $=$ not tested.

${ }^{\mathrm{b}} \mathrm{PVA}=$ Potato virus A, TuMV = Turnip mosaic virus, and NIa = nuclear inclusion protein a.

${ }^{c}$ Interaction was observed only when VPg or NIa was fused to the activation domain and S6K to the DNA-binding domain.
} 
et al. 2007). Such responses were observed to TuMV in Arabidopsis and to PPV in N. benthamiana. However, there has not been evidence that elevated mRNA expression leads to corresponding increases in protein levels. Here, we showed that levels of RPS6 protein are, indeed, higher in plants infected with TuMV and also the other viruses tested. Therefore, induction of r-protein expression appears to be a response that is not unique to potyviruses.

In animals, RPS6 has been shown to have critical physiological functions in global protein synthesis; cell survival, proliferation, and development; glucose homeostasis; and so on (Byrne 2009; Ishii et al. 2009; Meyuhas 2008); and it also undergoes reprogramming mRNA translation during stress (Yamasaki and Anderson 2008). RPS6 can associate with alphavirus nonstructural protein 2 and mediate expression from alphavirus messages (Montgomery et al. 2006). Further work is needed to determine how RPS6 becomes induced in response to infection by diverse plant viruses and in which ways RPS6 interacts with plant viruses.

All positive-strand RNA virus genomes must fulfill multiple, seemingly conflicting functions. Upon entering host cells, the genomes must be translated to produce viral replication proteins, which then recognize the viral RNA and recruit it out of translation into membrane-bound viral replication complexes (Noueiry and Ahlquist 2003). Due to varied genetic organization, viruses have different translation initiation and replication strategies. The genomic RNA of CMV have 5' cap structures and $3^{\prime}$ conserved regions that can fold into tRNA-like structures. During translation initiation, the multisubunit cap-binding eIF4F complex interacts with the $5^{\prime}$ cap and, along with other factors, recruits the 40S ribosomal subunit to the mRNA. tRNA-like elements in the $3^{\prime}$ untranslated region (UTR) of CMV play important roles in coregulating translation, recruitment, and replication (Noueiry and Ahlquist 2003; Roossinck 2001). TMV genomic and subgenomic RNA also possess a $5^{\prime}$ m7Gppp cap and a $3^{\prime}$ tRNA-like structure (Guilley et al. 1979; Richards et al. 1978). The 5' UTR of TMV also contains a translation enhancer element known as the $\Omega$ leader (Sleat et al. 1987). Hence, TMV translation is thought to be facilitated by both the m7Gppp cap and the $\Omega$ leader as well as other factors.

TCV and the potyviruses (TuMV and PVA) utilize capindependent translation mechanisms. The $3^{\prime}$-UTR of TCV genomic RNA contains a cap-independent translational enhancer, which includes a ribosome-binding structural element that participates in recruitment of $60 \mathrm{~S}$ ribosomal subunits and is involved in viral translation or replication processes (Stupina et al. 2008; Yuan et al. 2009; Zuo et al. 2010). Potyviruses possess a VPg, which is covalently linked to the $5^{\prime}$ terminus of their RNA. There is evidence indicating that an internal ribosome entry site mediates the translation of potyvirus RNA (Basso et al. 1994; Gallie 2001). All of the above information demonstrates that the four kinds of viruses used in our experiments employ different translation and gene-expression strategies.

RPS6 is located in the interface between the two ribosomal subunits, and there is evidence that it can interact with mRNA, tRNA, translation initiation factor (eIF2), and the 28S rRNA, suggesting that it might be involved in initiation of translation (Nygård and Nilsson 1990). Based on the data presented here and in our previous study, plant RNA viruses differ in their requirements of RPS6 for infection in N. benthamiana (Yang et al. 2009). TuMV, PVA, and CMV required RPS6, whereas TCV and TMV did not. We had previously concluded that there may be a link between cap-independent translation and a requirement for RPS6 for plant virus infection (Yang et al. 2009), which was consistent with results obtained earlier from experiments examining the effects of depleting r-proteins on viral replication in D. melanogaster and human cells (Cherry et al. 2005). However, the observation that CMV also requires RPS6, whereas TCV does not, suggests that there are other factors involved in the dependence on RPS6 in addition to the presence or absence of the $5^{\prime}$ cap structure.

RPS6 is one of many targets that is phosphorylated by S6K, a serine/threonine kinase (Magnuson et al. 2012). S6K is regulated by a variety of environmental and developmental stimuli, including infection by some DNA and RNA viruses infecting human and animal hosts (Holz and Blenis 2005; Holz et al. 2005; Meyuhas 2008; Moore et al. 2009). It is also a downstream component of the TOR signaling pathway (Xiong and Sheen 2014). S6K is a central factor in regulating cell growth and energy metabolism, integrating signals from growth factors, mitogens, life span, nutrients, and stresses. For example, S6K-deficient mice and Drosophila spp. display a small phenotype, and S6K1 can lead to increased life span and resistance to age-related pathologies in mammals such as bone, immune, and motor dysfunction and loss of insulin sensitivity (Jastrzebski et al. 2007; Selman et al. 2009).

In Arabidopsis, S6K are needed for maintenance of chromosome stability and ploidy levels, and negatively regulate cell proliferation (Henriques et al. 2010). In our experiment, the phenotypes of $S 6 K$-silenced $N$. benthamiana plants mimicked those of RPS6-deficient $N$. benthamiana plants that displayed chlorotic leaves and dwarfism. The severe effects of $S 6 K$ silencing on plant growth are in agreement with the case in animals, where S6K is a key regulator of growth. In plants, RPS6 phosphorylation is altered under conditions such as osmotic stress, cold stress, heat
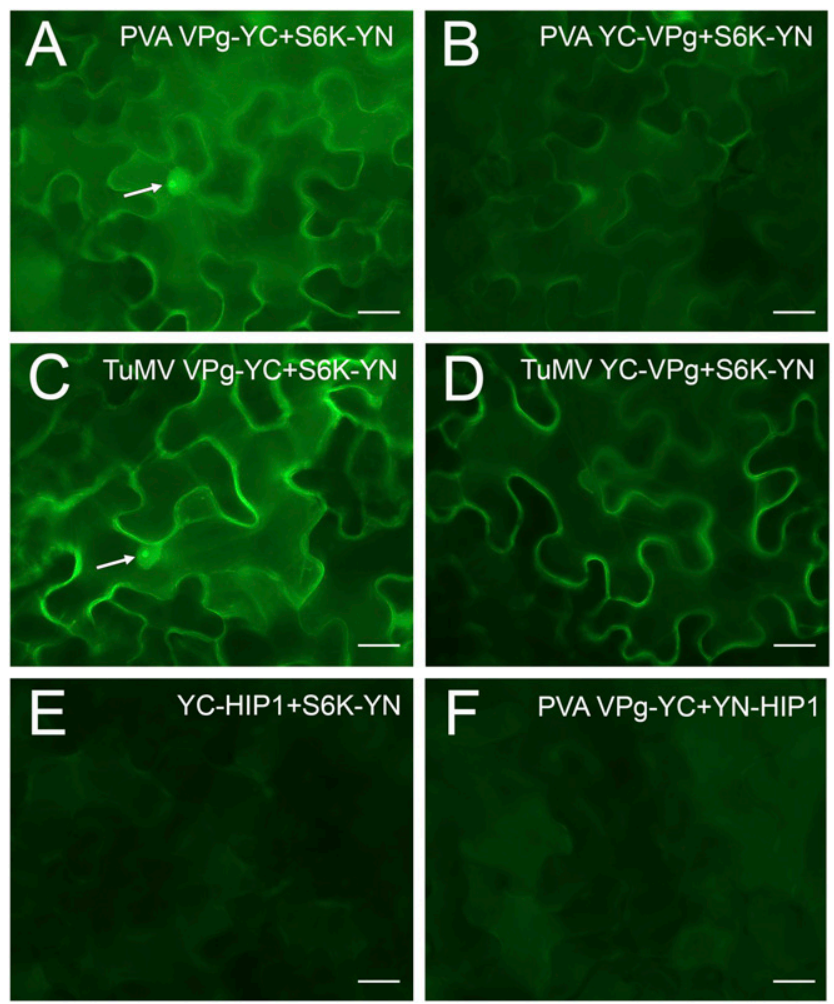

Fig. 7. Detection of interactions between Potato virus A (PVA) or Turnip mosaic virus (TuMV) viral genome-linked proteins (VPg) with Arabidopsis S6K2 in epidermal cells of leaves of Nicotiana benthamiana using bimolecular fluorescence complementation. $\mathbf{A}$ and $\mathbf{B}$, Interactions between PVA-VPg and AtS6K2-YN; $\mathbf{C}$ and D, interactions between TuMV-VPg and AtS6K2-YN; E and F, coexpression of HIP1 and AtS6K2 or VPg (negative controls). Leaves were infiltrated with pairs of Agrobacterium strains expressing proteins tagged with the different halves of yellow fluorescent protein. Images were taken using an epifluorescence microscope 2 days postinfiltration using the same exposure time. Arrows (A and C) indicate the position of the nucleus. Scale bars $=20 \mu \mathrm{m}$. 
shock, and oxygen deprivation (Mahfouz et al. 2006; Williams et al. 2003). However, we were unable to show that plant viruses can also influence the phosphorylation status of RPS6 despite the observation that silencing $S 6 K$ had negative effects on CMV, TuMV, and PVA. It is possible that RPS6 is not differentially phosphorylated in response to these viruses, or that our experimental system may lack sufficient sensitivity or resolution to detect changes in its phosphorylation. Alternatively, potyviruses and CMV may require S6K to phosphorylate other targets (host or viral) to promote their infections. Future studies investigating the phosphoproteome of virus-infected plants are warranted, because S6K has several other possible substrates based on the mammalian literature (Magnuson et al. 2012).

As a component of ribosomes, we expected RPS6 to show a ribosomal localization pattern. In our study, potato RPS6-GFP was detected almost entirely in the nucleus and nucleolus when expressed in the epidermal cells of $N$. benthamiana. The nucleolus is the site for rRNA synthesis and ribosome biogenesis (Boisvert et al. 2007) and, thus, the visible localization of RPS6 seemed to match with the site of ribosome assembly. Likewise, GFP-tagged
Arabidopsis RPS6 localizes in the nucleus when expressed alone in Arabidopsis protoplasts (Kim et al. 2014). However, GFP-tagged potato S6K, the regulator of RPS6, localized in cytoplasm and was not visible in the nucleus. Based on previous studies, two S6K homologs (S6K1 and S6K2) of Arabidopsis show slightly different subcellular localization. GFP-tagged AtS6K2 localizes mainly to the nucleus and nucleolus, whereas GFP-tagged AtS6K1 shows a more cytoplasmic localization pattern (Mahfouz et al. 2006). The potato S6K protein cloned in this study has 66.3 and $64.5 \%$ amino acid identity to AtS6K1 and AtS6K2, respectively. The cytoplasmic localization of the cloned StS6K suggests that it may be functionally more similar to AtS6K1. Previous studies have shown that AtS6K1 can phosphorylate RPS6 and suggest that it is regulated by the TOR signaling pathway in plants, whereas AtS6K2 may regulate RPS6 phosphorylation in the nucleus (Mahfouz et al. 2006).

Our results indicate that both PVA and TuMV VPg are able to interact with AtS6K2, as shown by BiFC analysis. In addition, PVA-VPg interacted with AtS6K2 and StS6K in YTHS. The $\mathrm{BiFC}$ interaction localized in both the cytoplasm and the
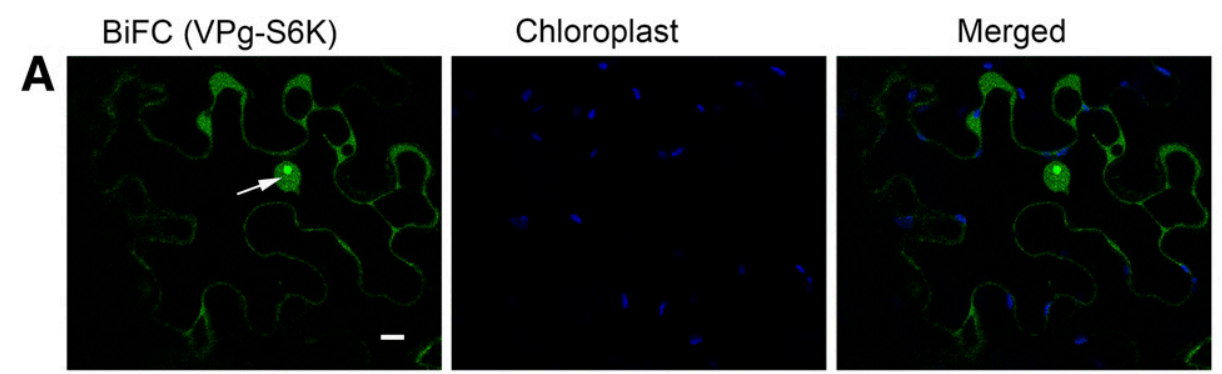

B
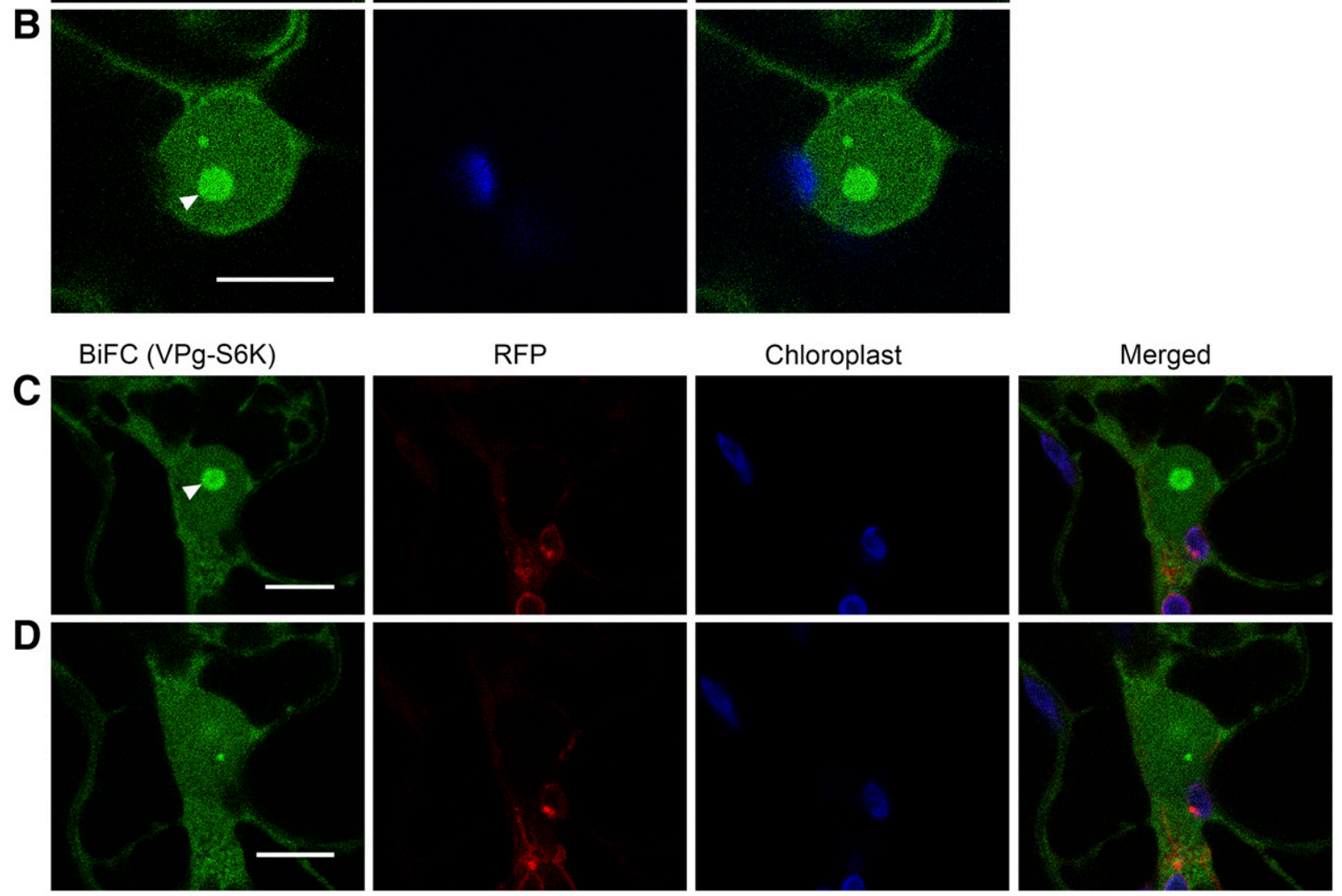

D
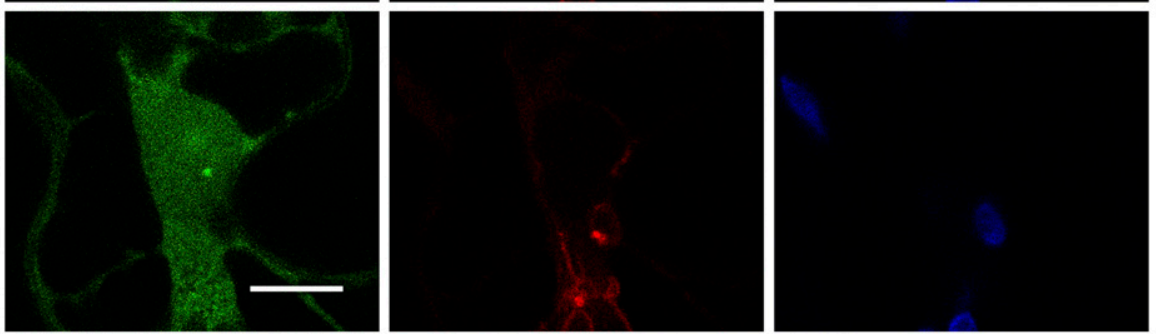

Fig. 8. Localization of the viral genome-linked protein (VPg)-AtS6K2 interaction in epidermal cells of Nicotiana benthamiana using bimolecular fluorescence complementation (BiFC). A and $\mathbf{B}$, Potato virus A (PVA) VPg-AtS6K2 interaction is detected in cytoplasm and nucleus. Arrow indicates the position of nucleus. B, In the nucleus, the fluorescence is concentrated in the nucleolus (arrowhead) and subnuclear bodies. $\mathbf{C}$ and $\mathbf{D}$, BiFC interaction between PVA VPgYC and AtS6K2-YN (green color) does not colocalize with 6K2-monomeric red fluorescence protein (mRFP)-derived viral replication vesicles in PVAinfected cells. 6K2-mRFP is expressed from the genome of PVA. Pictures are single optical sections captured by a confocal microscope 2 to 3 days postinfiltration. Scale bars $=10 \mu \mathrm{m}$. 
nucleus and, in the nucleus, the interaction concentrated heavily in the nucleolus and several small subnuclear bodies. Also, the interaction between PVA-VPg and StS6K was detected in the nucleus although, in this case, the BiFC interaction was much weaker than with AtS6K2. Thus, the localization of the $\mathrm{VPg}-\mathrm{S} 6 \mathrm{~K}$ interaction was different from the localization of GFP-StS6K, which was visible only in the cytoplasm. We cannot exclude, however, that GFP-StS6K was also present in the nucleus but in amounts too low to be detected. Thus, the data indicate that VPg interacts with S6K in both the cytoplasm and the nucleus but whether VPg promotes S6K nuclear localization or interacts with the nuclear pool of S6K cannot be specified.

In addition to being a component of the $40 \mathrm{~S}$ ribosomal subunit, a novel extraribosomal function in regulating rRNA transcription has been recently described for Arabidopsis RPS6 (Kim et al. 2014). RPS6 interacts with histone deacetylase 2B (HD2B) to facilitate nucleolar localization of RPS6. In the nucleolus, RPS6 binds to the rDNA promoter regions, which leads to repression of rDNA transcription via the RPS6-HD2B complex (Kim et al. 2014). RPS6 can also bind to nucleosome assembly protein 1, which instead appears to have a positive effect on rDNA transcription (Son et al. 2015). S6K can also affect rDNA transcription and, during active ribosome biogenesis, RPS6 is phosphorylated in the nucleolus (Kim et al. 2014; Son et al. 2015). Therefore, the authors have suggested that RPS6 phosphorylation by S6K in the nucleus may cause dissociation of the transcriptional repression complex and activate rDNA transcription (Kim et al. 2014; Son et al. 2015). In this study, $\mathrm{VPg}-\mathrm{S} 6 \mathrm{~K}$ interaction was detected in the cytoplasm and also in the nucleus and nucleolus. The nuclear interaction of VPg-S6K might promote phosphorylation of nuclear RPS6 and activation of rDNA transcription. This scenario is consistent with several previous studies demonstrating that expression of r-proteins increases during potyvirus infection (Dardick 2007; Yang et al. 2007). On the other hand, cytoplasmic RPS6 phosphorylation promotes protein translation and is regulated by various stress signals (Fumagalli and Thomas 2000; Warner and McIntosh 2009), including the infections of some human and animal viruses (Holz and Blenis 2005; Holz et al. 2005; Meyuhas 2008; Moore et al. 2009). However, whether RPS6 phosphorylation was differently affected in the nucleus and cytoplasm was not studied.

In conclusion, our results indicate that, although many viruses appear to increase expression of RPS6 in virus-infected plant cells, the requirements of RPS6 and S6K for plant RNA virus infection are largely dependent on the virus. The interaction between potyvirus $\mathrm{VPg}$ and $\mathrm{S} 6 \mathrm{~K}$ also suggests that potyviruses may recruit S6K to regulate their downstream target proteins, including RPS6, for their benefit. Further studies are needed to better understand these mechanisms because of the importance of RPS6 and S6K in regulating key cellular processes such as translation in response to environmental stimuli. These host proteins have dramatic influences on viral infection, making them potential candidates for future viruscontrol strategies.

\section{MATERIALS AND METHODS}

\section{Plant material.}

$N$. benthamiana plants were grown from seed in growth chambers, under a 16-h photoperiod, with light intensity of $250 \mu \mathrm{E} \mathrm{m}^{-2} \mathrm{~s}^{-1}$ and temperatures of 23 and $20^{\circ} \mathrm{C}$ during the day and night, respectively. The plants were watered as needed and fertilized with $1 \%$ fertilizer $(\mathrm{N}-\mathrm{P}-\mathrm{K}=16: 9: 22)$ (Yara, Espoo, Finland).

Virus inoculum for sap inoculations.

CMV (strain XJ1) (Xi et al. 2006) and TCV were mechanically inoculated and propagated in $N$. benthamiana. Inoculum was prepared by grinding leaves $1: 5(\mathrm{wt} / \mathrm{vol})$ in $20 \mathrm{mM}$ phosphate buffer ( $\mathrm{pH}$ 7.2). TuMV-GFP inoculum was prepared from leaves of $N$. benthamiana plants that had been inoculated with p35STuMV-GFP (Lellis et al. 2002). TMV-GFP inoculum was prepared from leaves of $N$. benthamiana plants that were infiltrated with Agrobacterium tumefaciens strain GV3101 carrying the infectious TMV-GFP genome (Jin et al. 2002). The TuMV-GFP- and TMV-GFP-infected leaves were stored in aliquots at $-80^{\circ} \mathrm{C}$ and, for inoculation, they were ground 1:5 (wt/vol) in $20 \mathrm{mM}$ potassium phosphate buffer, $\mathrm{pH}$ 7.2.

\section{Western blot analysis.}

Proteins were extracted as described (Moffett et al. 2002), separated by PAGE using $4.5 \%$ stacking and $12.5 \%$ resolving polyacrylamide with SDS running buffer ( $25 \mathrm{mM}$ Tris [pH 8.3], $192 \mathrm{mM}$ glycine, and 1\% SDS). Protein was transferred to polyvinylidene difluoride membrane (Bio-Rad, Hercules, CA, U.S.A.) by electroblotting. Protein transfer and equal loading was estimated by staining the membranes with Ponceau S solution $(0.1 \%$ [wt/vol] in $5 \%$ acetic acid [vol/vol] $)$. For immunoblot assay, the membranes were incubated in 5\% nonfat dry milk/phosphate-buffered saline with Tween blocking buffer (20 mM Tris- $\mathrm{HCl}$ [pH 7.5], $150 \mathrm{mM} \mathrm{NaCl}$, and $0.05 \%$ Tween 20) for $3 \mathrm{~h}$, then incubated overnight at $4^{\circ} \mathrm{C}$ with a maize RPS6 antiserum diluted 1:1250 (Williams et al. 2003). The membranes were incubated with goat antirabbit immunoglobulin-G conjugated with alkaline phosphatase $(1: 10,000$ dilution) (Sigma-Aldrich, St. Louis) for $1 \mathrm{~h}$ at room temperature. The membrane blot images were developed using 1-Step NBT/BCIP (Pierce, Waltham, MA, U.S.A.).

\section{Construction of VIGS-silencing vectors.}

The sequences of $S 6 K$ used for VIGS were amplified from $N$. benthamiana cDNA using PrimeSTAR HS DNA Polymerase (TaKaRa Bio, Mountain View, CA, U.S.A) and the following oligonucleotide primers: NbRPSK6F (5'-CACCTGAAT CAAGCAGATCTAA-3') and NbRPSK6R (5'- CCAAGGATT TGGTGCTACATAA-3'). Because the $N$. benthamiana sequence for the $S 6 K$ gene was not available, sequences from $S$. lycopersicum (AY796114) were used in primer design. The 515-bp NbS6K PCR product corresponding to nucleotide positions 873 to 1,387 of the $S 6 K$ gene of $S$. lycopersicum was first TOPO-cloned into the pENTR vector (Invitrogen, Carlsbad, CA, U.S.A.) containing the attL1 and attL2 recombination sites and then recombined into pTRV2-attR2-attR1 destination vector (Dinesh-Kumar et al. 2003) using the LR CLONASE enzyme (Invitrogen) (Liu et al. 2002) to create pTRV:NbS6K.

\section{VIGS of RPS6 and S6K in N. benthamiana.}

pTRV1, pTRV2 (empty vector), pTRV2:NbRPS6 (previously described by Yang et al. 2009), and pTRV2:NbS6K plasmids were introduced into A. tumefaciens strain GV2260. Overnight cultures of Agrobacterium were grown at $28^{\circ} \mathrm{C}$ in Luria-Bertani medium containing kanamycin at $50 \mathrm{mg} / \mathrm{liter}$, ampicillin at $50 \mathrm{mg} /$ liter, rifampicin at $25 \mathrm{mg} /$ liter, streptomycin at $50 \mathrm{mg} /$ liter, $10 \mathrm{mM}$ 2-(N-morpholino)ethanesulfonic acid (MES), and $20 \mu \mathrm{M}$ acetosyringone. Agrobacterium cells were pelleted and resuspended in infiltration media $(10 \mathrm{mM} \mathrm{MgCl} 2,10 \mathrm{mM}$ MES, and $200 \mu \mathrm{M}$ acetosyringone), adjusted to an optical density at $600 \mathrm{~nm}\left(\mathrm{OD}_{600}\right)=0.8$, and incubated at room temperature for at least 3 h. The Agrobacterium sample carrying pTRV1 was mixed in a 1:1 ratio with pTRV2 or its derivatives and infiltrated into $N$. benthamiana leaves. The age of $N$. benthamiana plants and the positions of leaves suitable for efficient VIGS with the TRV system was determined using a TRV vector carrying a segment of the phytoene desaturase gene that causes photobleaching as a visible marker (Liu et al. 2002). 


\section{Agrobacterium inoculation and GFP imaging.}

pCB-TuMV-GFP, pCAMBIA-PVA-GFP, and pTMV-GFP were used for agroinoculation of TuMV-GFP, PVA-GFP, and TMV-GFP, respectively (Ala-Poikela et al. 2011). At 10 or 14 days after inoculation with TRV constructs, leaves of $N$. benthamiana plants with obvious VIGS loss-of-function phenotypes for RPS6 or S6K and corresponding leaves on the TRV2 empty vector plants were agroinfiltrated with TuMVGFP, TMV-GFP $\left(\mathrm{OD}_{600}=0.8\right)$, or PVA-GFP $\left(\mathrm{OD}_{600}=0.05\right)$, respectively. The $+3,+4$, and +5 leaves above the TRV agroinoculated leaves were used for all virus inoculation experiments. In each replication of the experiments, the corresponding leaves of control plants that were either not treated or were infected with the TRV empty vector (TRV::00) were included. GFP was visualized by UV illumination with a 100-W Blak-Ray longwave UV lamp (UVP, Upland, CA, U.S.A.) for development of GFP fluorescence and photographs were taken using a Nikon D70 digital camera fitted with a yellow Y2 filter or Canon EOS 40D camera.

\section{RNA isolation, RT-PCR, and Northern blots.}

To detect silencing of the target genes, total RNA was isolated from $N$. benthamiana leaves as previously described (Huang et al. 2005). RNA was treated with RNase-free DNaseI (Invitrogen), and it was used as template with the SuperScript III One-Step RT-PCR System (Invitrogen). Alternatively, Moloney

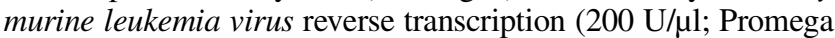
Corp., Madison, WI, U.S.A.) and random hexamers were used for cDNA synthesis, and quantitative PCR was carried out using Light Cycler 480 SYBR Green I PCR master mix (Roche, Mannheim, Germany) and the Light Cycler 480 real-time PCR detection system (Roche). The primers used to detect NbRPS6 and NbS6K transcripts are provided in Supplementary Table S1, and they amplified regions of the target genes that did not overlap with the VIGS inserts. For the viruses, quantitative RT-PCR was used to detect the expression of PVA-GFP and TuMV-GFP, whereas CMV, TCV, and TMV were detected by Northern blot hybridization (Zhang and Ghabrial 2006). Phos2A was used for an internal control for data normalization of qPCR.

\section{Extraction of r-proteins.}

The r-proteins were extracted using the method described by Williams et al. (2003), with some modification. Leaf tissue (3 to $4 \mathrm{~g}$ fresh weight) was ground in liquid nitrogen, homogenized in ribosome extraction buffer (200 mM Tris-HCl [pH 7.5], $200 \mathrm{mM}$ $\mathrm{KCl}, 25 \mathrm{mM}$ EGTA, $36 \mathrm{mM} \mathrm{MgCl}, 1 \mathrm{mM}$ sodium molybdate, $1 \mathrm{mM}$ dithiothreitol [DTT], cyclohexamide at $50 \mu \mathrm{g} / \mathrm{ml}$, chloramphenicol at $50 \mu \mathrm{g} / \mathrm{ml}, 80 \mathrm{mM} \beta$-glycerophosphate, $1 \%$ [vol $/ \mathrm{vol}]$ Triton X-100, $1 \%$ [vol/vol] Brij 35, $1 \%$ [vol/vol] Tween-40, and $1 \%$ [vol/vol] NP-40), and incubated on ice for $20 \mathrm{~min}$. Cell debris was removed by centrifugation at $10,000 \times g$ for $15 \mathrm{~min}$ at $4^{\circ} \mathrm{C}$. The supernatant was layered over a sucrose cushion $(1.3 \mathrm{M}$ sucrose, $400 \mathrm{mM}$ Tris-HCl [pH 7.5], $200 \mathrm{mM} \mathrm{KCl,} 5 \mathrm{mM}$ EGTA, $36 \mathrm{mM} \mathrm{MgCl} 2,1 \mathrm{mM}$ sodium molybdate, $1 \mathrm{mM}$ DTT, cyclohexamide at $50 \mu \mathrm{g} / \mathrm{liter}$, chloramphenicol at $50 \mu \mathrm{g} / \mathrm{ml}$, and $80 \mathrm{mM}$ $\beta$-glycerophosphate), and ribosomes were pelleted by centrifugation for $18 \mathrm{~h}$ at $150,000 \times g$. Ribosomes were resuspended in Staehlin A buffer (20 mM Tris- $\mathrm{HCl}$ [pH 7.5], $5 \mathrm{mM} \mathrm{MgCl} 2,1 \mathrm{mM}$ sodium molybdate, and $1 \mathrm{mM}$ DTT) by rotation of the sample for $1 \mathrm{~h}$ at $4^{\circ} \mathrm{C}$. Then, the crude ribosomes were diluted in 0.1 volume of $1 \mathrm{M} \mathrm{MgCl}_{2}$ and 2 volumes of glacial acetic acid, vortexed for $1 \mathrm{~h}$ at $4^{\circ} \mathrm{C}$, and centrifuged for $10 \mathrm{~min}$ at $4^{\circ} \mathrm{C}$ and $14,000 \times g$ to remove rRNA.

\section{Pro-Q Diamond phosphoprotein gel stain and SYPRO Ruby protein stain.}

Phosphorylated and total proteins present in the r-protein preparations were stained using a Pro-Q Diamond phosphoprotein gel stain kit and SYPRO Ruby protein gel stain kit (Invitrogen).
The r-proteins were treated with four volumes of methanol, one volume of chloroform, and three volumes of ultrapure water, vortexed, and centrifuged at 12,000 rpm for $5 \mathrm{~min}$. The upper phase was discarded and the lower phase, along with the white precipitate that formed between the two phases, was mixed with three volumes of methanol and centrifuged at 12,000 rpm for $5 \mathrm{~min}$. The pellets were air dried and resuspended in standard $1 \times$ sample buffer $(40 \mathrm{mM}$ Tris- $\mathrm{HCl}$ [pH 6.8], $10 \%$ glycerol, $2 \%$ SDS, $5 \% \beta$-mercaptoethanol, and $0.1 \%$ bromophenol blue) for electrophoresis. The gels were fixed in $50 \%$ methanol with $10 \%$ acetic acid for $30 \mathrm{~min}$, the solution was changed, and the fixation continued overnight, followed by washing three times for $10 \mathrm{~min}$ each in water. Immediately prior to use, the Pro-Q Diamond stain was equilibrated to room temperature and vigorously mixed. Gels were stained for $90 \mathrm{~min}$ in darkness, then destained by washing three times for $30 \mathrm{~min}$ each with $20 \%$ acetonitrile in $50 \mathrm{mM}$ sodium acetate $(\mathrm{pH} 4.0)$ followed by two washes in water. Stained proteins were visualized with UV light using a Bio-Rad imaging system or using fluorescent image analyzer FLA-5000 (Fuji Photo Film Co., Ltd., Tokyo) at $532 \mathrm{~nm}$. The gels were then immediately placed into SYPRO Ruby total protein stain and incubated overnight, followed by two washes in $10 \%$ methanol and $7 \%$ acetic acid, and finally two washes with water. Total protein was detected on a Bio-Rad imaging system at $300 \mathrm{~nm}$ or on an FLA-5000 image analyzer at $473 \mathrm{~nm}$.

\section{Yeast two-hybrid assays.}

Total RNA was extracted from the leaves of Arabidopsis (Col-0) and the leaves of a diploid potato (S. tuberosum) line v2-134 (Hämäläinen et al. 2000) with TRizol (Invitrogen), according to manufacturer's instructions, followed by mRNA isolation with Oligotex mRNA midi-kit (Qiagen, Hilden, Germany). cDNA was synthesized from 1 to $2 \mu \mathrm{g}$ of total RNA or mRNA using SuperScirpt III reverse transcription (Invitrogen) and random hexamers. The genes encoding for RPS6 and S6K of Arabidopsis (AtRPS6, AtS6K1, and AtS6K2) and RPS6 and S6K of potato (StRPS6 and StS6K) were amplified with PCR from the cDNA using Phusion high-fidelity DNA polymerase (Finnzymes, Espoo, Finland) and primers were designed based on the corresponding gene sequences of Arabidopsis or potato and containing the appropriate restriction sites for cloning. TuMV-VPg was amplified from the cDNA clone of TuMV using VPg-specific primers, accordingly. The amplified fragments were cloned into yeast two-hybrid vectors pGBKT7 and pGADT7 in frame with the GAL4 DNA BD and AD, respectively (Matchmaker Gal4 Yeast Two-Hybrid System 3; Clontech, Mountain View, CA, U.S.A.), and verified by sequencing. The YTHS vectors for expression of PVA VPg and NIa have been described (Oruetxebarria et al. 2002).

The $\mathrm{BD}$ and $\mathrm{AD}$ plasmids were cotransformed into yeast cells (strain AH109) using a small-scale lithium acetate method (Clontech). Protein-protein interactions were detected based on growth of yeast on selection medium lacking adenine, histidine, tryptophan, and leucine at $30^{\circ} \mathrm{C}$, which was observed for up to 10 days. Fusion protein expression in yeast was verified by Western blot analysis using monoclonal AD and BD antibodies (Clontech), as previously described (Ala-Poikela et al. 2011).

\section{BiFC.}

The genes encoding AtS6K2 and StS6Ka were amplified from the corresponding YTHS clones with primers containing the appropriate restriction sites for cloning. TuMV-VPg was amplified from the TuMV clone. The PCR fragments were cloned into the previously described binary vectors $\mathrm{pLH}-\mathrm{YN}$ and $\mathrm{pLH}$ YC (Zamyatnin et al. 2006). BiFC is based on splitting YFP into two nonfluorescent halves - the N-terminal fragment (YN, 
1 to 154 ) and the C-terminal fragment (YC, 155 to 239) - that are expressed in fusion with test proteins. If the test proteins interact with each other, the YFP is reconstituted, resulting in visible fluorescence. To clone the gene to be expressed as an $\mathrm{N}$-terminal fusion with $\mathrm{YN}$ or YC, primers containing the XhoI restriction site were used, whereas primers containing the NcoI site were used to clone the genes to be expressed as a C-terminal fusion with the corresponding YFP halves. All constructs were verified by sequencing.

The binary vectors were introduced into A. tumefaciens (Ti plasmid pGV2260) cells by electroporation using Bio-Rad Gene Pulser. Agroinfiltration into leaves of $N$. benthamiana was carried out as previously described (Rajamäki and Valkonen 2009).

\section{Construction of GFP-tagged fusion proteins.}

To construct pRT-GFP-StS6K, pRT-GFP-StRPS6, pRTStS6K-GFP, and pRT-StRPS6-GFP, the StS6Ka and StRPS6a genes were amplified from the corresponding YTHS clones with appropriate primers containing necessary restriction sites for cloning. The PCR products were cloned into the intermediate pRT-GFP vectors, as previously described (Rajamäki and Valkonen 2009). Subsequently, binary vectors were prepared by transferring the aforementioned expression cassettes, including the $35 \mathrm{~S}$ promoter from the pRT vector backbone, to the binary vector pKOH200 using HindIII.

\section{Fluorescence microscopy.}

A Leitz Laborlux S microscope with an epifluorescence extension Leitz Ploemopak (Leica Microsystems GmbH, Wetzlar, Germany) and appropriate filters (excitation 470/40 nm, emission $525 / 50 \mathrm{~nm}$ ) were used for visualization of the GFP and YFP. Images were captured using the charge-coupled device camera DP-50 (Olympus, Tokyo), which was controlled by Viewfinder Lite, version 1.0 software (Olympus). Alternatively, a Zeiss epifluorescence microscope (Axioimager M2; Carl Zeiss Microscopy GmbH, Jena, Germany) and a YFP-compatible filter cube (GFP) were used.

Confocal microscopy was carried out using Leica TCS SP2 AOBS device and $\times 63$ water immersion objective at the Institute of Biotechnology, University of Helsinki. Emission from GFP and RFP was scanned sequentially as follows: GFP was excited with and argon laser at $488 \mathrm{~nm}$ and captured at 500 to $550 \mathrm{~nm}$, and RFP was excited with a 561-nm DPSS laser and captured at 600 to $640 \mathrm{~nm}$. YFP resulting from BiFC was excited with a 514-nm argon laser and captured at 520 to $580 \mathrm{~nm}$. Chloroplast autofluorescence was excited with a 514-nm argon laser and captured at 650 to $700 \mathrm{~nm}$.

\section{ACKNOWLEDGMENTS}

We thank S. P. Dinesh-Kumar (University of California, Davis) for pTRV1, pTRV2-attR2-attR1, and pTRV2-NbPDS; B. Baker (University of California, Berkeley) for the TMV-GFP infectious clone; J. Bailey-Serres (University of California, Riverside) for maize RPS6 antiserum; J. C. Carrington (Danforth Plant Science Center) for TuMV-GFP binary plasmid; and A. E. Simon (Department of Cell Biology and Molecular Genetics, University of Maryland) for providing the infectious cDNA clone of TCV. This research was supported by the Academy of Finland (grant 1253126 to J. P. T. Valkonen), China Scholarship Council (grant 2008106602 to D. Xi), United States Department of Agriculture-National Institute of Food and Agriculture (Hatch Act, project 3708), and State of Iowa Funds.

\section{LITERATURE CITED}

Ala-Poikela, M., Goytia, E., Haikonen, T., Rajamäki, M.-L., and Valkonen, J. P. T. 2011. Helper component proteinase of the genus Potyvirus is an interaction partner of translation initiation factors eIF(iso)4E and eIF4E and contains a 4E binding motif. J. Virol. 85:6784-6794.
Basso, J., Dallaire, P., Charest, P. J., Devantier, Y., and Laliberté, J. F. 1994 Evidence for an internal ribosome entry site within the $5^{\prime}$ non-translated region of turnip mosaic potyvirus RNA. J. Gen. Virol. 75:3157-3165.

Boisvert, F. M., van Koningsbruggen, S., Navascués, J., and Lamond, A. I. 2007. The multifunctional nucleolus. Nat. Rev. Mol. Cell Biol. 8: 574-585.

Bureau, M., Leh, V., Haas, M., Geldreich, A., Ryabova, L., Yot, P., and Keller, M. 2004. P6 protein of Cauliflower mosaic virus, a translation reinitiator, interacts with ribosomal protein L13 from Arabidopsis thaliana. J. Gen. Virol. 85:3765-3775.

Byrne, M. E. 2009. A role for the ribosome in development. Trends Plant Sci. 14:512-519.

Chang, I. F., Szick-Miranda, K., Pan, S., and Bailey-Serres, J. 2005. Proteomic characterization of evolutionarily conserved and variable proteins of Arabidopsis cytosolic ribosomes. Plant Physiol. 137:848-862.

Chen, F. W., and Ioannou, Y. A. 1999. Ribosomal proteins in cell proliferation and apoptosis. Int. Rev. Immunol. 18:429-448.

Cherry, S., Doukas, T., Armknecht, S., Whelan, S., Wang, H., Sarnow, P., and Perrimon, N. 2005. Genome-wide RNAi screen reveals a specific sensitivity of IRES-containing RNA viruses to host translation inhibition. Genes Dev. 19:445-452.

Cotton, S., Grangeon, R., Thivierge, K., Mathieu, I., Ide, C., Wei, T., Wang, A., and Laliberté, J.-F. 2009. Turnip mosaic virus RNA replication complex vesicles are mobile, align with microfilaments, and are each derived from a single viral genome. J. Virol. 83:10460-10471.

Creff, A., Sormani, R., and Desnos, T. 2010. The two Arabidopsis RPS6 genes, encoding for cytoplasmic ribosomal proteins S6, are functionally equivalent. Plant Mol. Biol. 73:533-546.

Dardick, C. 2007. Comparative expression profiling of Nicotiana benthamiana leaves systemically infected with three fruit tree viruses. Mol. Plant-Microbe Interact 20:1004-1017.

Dinesh-Kumar, S. P., Anandalakshmi, R., Marathe, R., Schiff, M., and Liu, Y. 2003. Virus-induced gene silencing. Methods Mol. Biol. 236:287-294.

Fumagalli, S., and Thomas, G. 2000. Phosphorylation and signal transduction. Pages 695-717 in: Translational Control of Gene Expression. J. W. Hershey, M. B. Mathews, and N. Sonenberg, eds. Cold Spring Harbor Laboratory Press, Cold Spring Harbor, NY.

Gallie, D. R. 2001. Cap-independent translation conferred by the $5^{\prime}$ leader of tobacco etch virus is eukaryotic initiation factor $4 \mathrm{G}$ dependent. J. Virol. 75:12141-12152.

Guilley, H., Jonard, G., Kukla, B., and Richards, K. E. 1979. Sequence of 1000 nucleotides at the $3^{\prime}$ end of tobacco mosaic virus RNA. Nucleic Acids Res. 6:1287-1308.

Hafrén, A., Eskelin, K., and Mäkinen, K. 2013. Ribosomal protein P0 promotes Potato virus $A$ infection and functions in viral translation together with VPg and eIF(iso)4E. J. Virol. 87:4302-4312.

Hämäläinen, J. H., Kekarainen, T., Gebhardt, C., Watanabe, K. N., and Valkonen, J. P. T. 2000. Recessive and dominant genes interfere with the vascular transport of Potato virus $A$ in diploid potatoes. Mol. PlantMicrobe Interact 13:402-412.

Henriques, R., Magyar, Z., Monardes, A., Khan, S., Zalejski, C., Orellana, J., Szabados, L., de la Torre, C., Koncz, C., and Bögre, L. 2010. Arabidopsis S6 kinase mutants display chromosome instability and altered RBR1-E2F pathway activity. EMBO J. 29:2979-2993.

Holz, M. K., Ballif, B. A., Gygi, S. P., and Blenis, J. 2005. mTOR and S6K1 mediate assembly of the translation preinitiation complex through dynamic protein interchange and ordered phosphorylation events. Cell 123: 569-580.

Holz, M. K., and Blenis, J. 2005. Identification of S6 kinase 1 as a novel mammalian target of rapamycin (mTOR)-phosphorylating kinase. J. Biol. Chem. 280:26089-26093.

Huang, Z., Yeakley, J. M., Garcia, E. W., Holdridge, J. D., Fan, J. B., and Whitham, S. A. 2005. Salicylic acid-dependent expression of host genes in compatible Arabidopsis-virus interactions. Plant Physiol. 137:1147-1159.

Ishii, K., Nakao, Y., Amagai, A., and Maeda, Y. 2009. Novel functions of ribosomal protein S6 in growth and differentiation of Dictyostelium cells. Dev. Growth Differ. 51:533-546.

Ivanov, K. I., Eskelin, K., Bašić, M., De, S., Lõhmus, A., Varjosalo, M., and Mäkinen, K. 2016. Molecular insights into the function of the viral RNA silencing suppressor HCPro. Plant J. 85:30-45.

Jastrzebski, K., Hannan, K. M., Tchoubrieva, E. B., Hannan, R. D., and Pearson, R. B. 2007. Coordinate regulation of ribosome biogenesis and function by the ribosomal protein S6 kinase, a key mediator of mTOR function. Growth Factors 25:209-226.

Jeon, Y. J., Kim, I. K., Hong, S. H., Nan, H., Kim, H. J., Lee, H. J., Masuda, E. S., Meyuhas, O., Oh, B. H., and Jung, Y. K. 2008. Ribosomal protein S6 is a selective mediator of TRAIL-apoptotic signaling. Oncogene 27:4344-4352. 
Jin, H., Axtell, M. J., Dahlbeck, D., Ekwenna, O., Zhang, S., Staskawicz, B., and Baker, B. 2002. NPK1, an MEKK1-like mitogen-activated protein kinase kinase kinase, regulates innate immunity and development in plants. Dev. Cell 3:291-297.

Kim, Y.-K., Kim, S., Shin, Y.-J., Hur, Y.-S., Kim, W.-Y., Lee, M.-S., Cheon, C. I., and Verma, D. P. S. 2014. Ribosomal protein S6, a target of rapamycin, is involved in the regulation of rRNA genes by possible epigenetic changes in Arabidopsis. J. Biol. Chem. 289:3901-3912.

Lellis, A. D., Kasschau, K. D., Whitham, S. A., and Carrington, J. C. 2002. Loss-of-susceptibility mutants of Arabidopsis thaliana reveal an essential role for eIF(iso)4E during potyvirus infection. Curr. Biol. 12:1046-1051.

Lindström, M. S. 2009. Emerging functions of ribosomal proteins in genespecific transcription and translation. Biochem. Biophys. Res. Commun. 379:167-170.

Liu, Y., Schiff, M., and Dinesh-Kumar, S. P. 2002. Virus-induced gene silencing in tomato. Plant J. 31:777-786.

Magnuson, B., Ekim, B., and Fingar, D. C. 2012. Regulation and function of ribosomal protein S6 kinase (S6K) within mTOR signalling networks. Biochem. J. 441:1-21.

Mahfouz, M. M., Kim, S., Delauney, A. J., and Verma, D. P. 2006. Arabidopsis TARGET OF RAPAMYCIN interacts with RAPTOR, which regulates the activity of S6 kinase in response to osmotic stress signals. Plant Cell 18:477-490.

Martínez, F., and Daròs, J.-A. 2014. Tobacco etch virus protein P1 traffics to the nucleolus and associates with the host $60 \mathrm{~S}$ ribosomal subunits during infection. J. Virol. 88:10725-10737.

Mazumder, B., Sampath, P., Seshadri, V., Maitra, R. K., DiCorleto, P. E., and Fox, P. L. 2003. Regulated release of L13a from the 60S ribosomal subunit as a mechanism of transcript-specific translational control. Cell 115:187-198.

Meyuhas, O. 2008. Physiological roles of ribosomal protein S6: One of its kind. Int. Rev. Cell Mol. Biol. 268:1-37.

Moffett, P., Farnham, G., Peart, J., and Baulcombe, D. C. 2002. Interaction between domains of a plant NBS-LRR protein in disease resistancerelated cell death. EMBO J. 21:4511-4519.

Montgomery, S. A., Berglund, P., Beard, C. W., and Johnston, R. E. 2006. Ribosomal protein S6 associates with alphavirus nonstructural protein 2 and mediates expression from alphavirus messages. J. Virol. 80: 7729-7739.

Moore, C. E. J., Xie, J., Gomez, E., and Herbert, T. P. 2009. Identification of cAMP-dependent kinase as a third in vivo ribosomal protein S6 kinase in pancreatic $\beta$-cells. J. Mol. Biol. 389:480-494.

Newburn, L. R., and White, K. A. 2015. Cis-acting RNA elements in positive-strand RNA plant virus genomes. Virology 479-480:434-443.

Nicholson, B. L., and White, K. A. 2011. 3' Cap-independent translation enhancers of positive-strand RNA plant viruses. Curr. Opin. Virol. 1: 373-380.

Noueiry, A. O., and Ahlquist, P. 2003. Brome mosaic virus RNA replication: Revealing the role of the host in RNA virus replication. Annu. Rev. Phytopathol. 41:77-98.

Nygård, O., and Nilsson, L. 1990. Translational dynamics. Interactions between the translational factors, tRNA and ribosomes during eukaryotic protein synthesis. Eur. J. Biochem. 191:1-17.

Oruetxebarria, I., Kvarnheden, A., and Valkonen, J. P. T. 2002. Analysis of putative interactions between potyviral replication proteins and plant retinoblastoma proteins. Virus Genes 24:65-75.

Panić, L., Montagne, J., Cokarić, M., and Volarević, S. 2007. S6haploinsufficiency activates the p53 tumor suppressor. Cell Cycle 6 : 20-24.

Rajamäki, M. L., and Valkonen, J. P. T. 2009. Control of nuclear and nucleolar localization of nuclear inclusion protein a of picorna-like Potato virus A in Nicotiana species. Plant Cell 21:2485-2502.

Richards, K., Guilley, H., Jonard, G., and Hirth, L. 1978. Nucleotide sequence at the $5^{\prime}$ extremity of tobacco-mosaic-virus RNA. 1. The noncoding region (nucleotides 1-68). Eur. J. Biochem. 84:513-519.

Robaglia, C., and Caranta, C. 2006. Translation initiation factors: A weak link in plant RNA virus infection. Trends Plant Sci. 11:40-45.
Rocha, C. S., Santos, A. A., Machado, J. P., and Fontes, E. P. 2008. The ribosomal protein L10/QM-like protein is a component of the NIKmediated antiviral signaling. Virology 380:165-169.

Roossinck, M. J. 2001. Cucumber mosaic virus, a model for RNA virus evolution. Mol. Plant Pathol. 2:59-63.

Selman, C., Tullet, J. M. A., Wieser, D., Irvine, E., Lingard, S. J., Choudhury, A. I., Claret, M., Al-Qassab, H., Carmignac, D., Ramadani, F., Woods, A., Robinson, I. C. A., Schuster, E., Batterham, R. L., Kozma, S. C., Thomas, G., Carling, D., Okkenhaug, K., Thornton, J. M., Partridge, L., Gems, D., and Withers, D. J. 2009. Ribosomal protein S6 kinase 1 signaling regulates mammalian life span. Science 326:140-144.

Semrad, K., Green, R., and Schroeder, R. 2004. RNA chaperone activity of large ribosomal subunit proteins from Escherichia coli. RNA 10: 1855-1860.

Sharma, S. D., Kraft, J. J., Miller, W. A., and Goss, D. J. 2015. Recruitment of the $40 \mathrm{~S}$ ribosome subunit to the $3^{\prime}$-untranslated region (UTR) of a viral mRNA, via the eIF4 complex, facilitates cap-independent translation. J. Biol. Chem. 290:11268-11281.

Sleat, D. E., Gallie, D. R., Jefferson, R. A., Bevan, M. W., Turner, P. C., and Wilson, T. M. 1987. Characterisation of the 5'-leader sequence of tobacco mosaic virus RNA as a general enhancer of translation in vitro. Gene 60:217-225.

Son, O., Kim, S., Shin, Y.-J., Kim, W.-Y., Koh, H.-J., and Cheon, C.-I. 2015. Identification of nucleosome assembly protein 1 (NAP1) as an interacting partner of plant ribosomal protein S6 (RPS6) and a positive regulator of rDNA transcription. Biochem. Biophys. Res. Commun. 465:200-205.

Stupina, V. A., Meskauskas, A., McCormack, J. C., Yingling, Y. G., Shapiro, B. A., Dinman, J. D., and Simon, A. E. 2008. The $3^{\prime}$ proximal translational enhancer of Turnip crinkle virus binds to $60 \mathrm{~S}$ ribosomal subunits. RNA 14:2379-2393.

Warner, J. R., and McIntosh, K. B. 2009. How common are extraribosomal functions of ribosomal proteins? Mol. Cell 34:3-11.

Wei, T., Huang, T.-S., McNeil, J., Laliberté, J.-F., Hong, J., Nelson, R. S., and Wang, A. 2010. Sequential recruitment of the endoplasmic reticulum and chloroplasts for plant potyvirus replication. J. Virol. 84:799-809.

Williams, A. J., Werner-Fraczek, J., Chang, I. F., and Bailey-Serres, J. 2003. Regulated phosphorylation of 40S ribosomal protein S6 in root tips of maize. Plant Physiol. 132:2086-2097.

Xi, D., Lan, L., Wang, J., Xu, W., Xiang, B., and Lin, H. 2006. Variation analysis of two cucumber mosaic viruses and their associated satellite RNAs from sugar beet in China. Virus Genes 33:293-298.

Xiong, Y., and Sheen, J. 2014. The role of target of rapamycin signaling networks in plant growth and metabolism. Plant Physiol. 164:499-512.

Yamasaki, S., and Anderson, P. 2008. Reprogramming mRNA translation during stress. Curr. Opin. Cell Biol. 20:222-226.

Yang, C., Guo, R., Jie, F., Nettleton, D., Peng, J., Carr, T., Yeakley, J. M., Fan, J. B., and Whitham, S. A. 2007. Spatial analysis of Arabidopsis thaliana gene expression in response to Turnip mosaic virus infection. Mol. Plant-Microbe Interact 20:358-370.

Yang, C., Zhang, C., Dittman, J. D., and Whitham, S. A. 2009. Differential requirement of ribosomal protein S6 by plant RNA viruses with different translation initiation strategies. Virology 390:163-173.

Yuan, X., Shi, K., Meskauskas, A., and Simon, A. E. 2009. The $3^{\prime}$ end of Turnip crinkle virus contains a highly interactive structure including a translational enhancer that is disrupted by binding to the RNA-dependent RNA polymerase. RNA 15:1849-1864.

Zamyatnin, A. A., Jr., Solovyev, A. G., Bozhkov, P. V., Valkonen, J. P. T., Morozov, S. Y., and Savenkov, E. I. 2006. Assessment of the integral membrane protein topology in living cells. Plant J. 46:145-154.

Zhang, C., and Ghabrial, S. A. 2006. Development of Bean pod mottle virus-based vectors for stable protein expression and sequence-specific virus-induced gene silencing in soybean. Virology 344:401-411.

Zuo, X., Wang, J., Yu, P., Eyler, D., Xu, H., Starich, M. R., Tiede, D. M., Simon, A. E., Kasprzak, W., Schwieters, C. D., Shapiro, B. A., and Wang, Y.-X. 2010. Solution structure of the cap-independent translational enhancer and ribosome-binding element in the $3^{\prime}$ UTR of turnip crinkle virus. Proc. Natl. Acad. Sci. U.S.A. 107:1385-1390. 